\title{
Sex Determination from Toeless Footprint Among Ibans, An Indiginenious Ethnic Group in Malaysian Borneo
}

\author{
Nataraja Moorthy $\mathrm{T}^{1 *}$ and Hairunnisa $\mathrm{MAK}^{2}$ \\ ${ }^{1}$ Management and Science University, Malaysia \\ ${ }^{2}$ Chemistry Department of Malaysia, Forensic Science Laboratory, Malaysia \\ *Corresponding author: Associate Professor of Forensic Sciences, Management and Science University, Shah Alam, Selangor, Malaysia
}

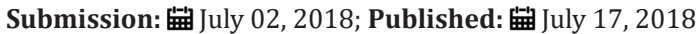

\begin{abstract}
In the current forensic scenarios, footprint examination is one of the most reliable methods for person identification. Footprints are used to estimate stature, living body weight, sex and ethnics identification. Determination of sex of footprints can help in establishing the biological profile of suspects. Footprint ridge density refers to the number of friction ridge demarcated areas. Ridge density shows forensic significance for sexual dimorphism and ethnicity should be considered whenever conducting anthropological investigation. There are some incidences wherein footprints without toes or smudged toes, i.e. partial footprints are found in the crime scenes and the investigators neglected the evidence, presuming unfit for analysis. Hence the present study was aimed to investigate the sexual dimorphism in the toeless footprints in Iban population, living in Malaysian Borneo.
\end{abstract}

Keywords: Forensic anthropology; Toeless footprint; Ridge density; Sex; Ibans, Malaysian Borneo

\section{Introduction}

Complex physical patterns are formed by the ridged skin on the fingers, palms of the hands and soles of the feet and toes. The fingers, palms, toes, and foot soles are all covered with friction ridges arrayed in a unique and relatively permanent pattern and even courts also accept this as evidence from all four areas [1-2]. Dermatoglyphic is a study of impression of hands and feet and is being utilized by the anthropologist and forensic scientists for numerous analyses [3]. Friction ridge patterns are considered unique to an individual and remain unchanged throughout life; thus, fingerprints and footprints are used in forensic investigations for identification purposes [4]. Footprint analysis is considered as a biometric technique used to obtain multiple information in crime scenes [5]. Friction ridge density refers to the number of ridges in a defined area on a print or mark and is influenced by ridges in a defined area on a print and is influenced by ridge width and the distances between ridges [6]. Anthropologists have presented their result findings in sex variation in the ridge densities of fingerprints [7,8], palm prints [9] and footprints [10].

Footprints found in crimes are used to estimate stature [1113] and body weight [14-16] for person identification. It is an established fact that footprints show individual characteristic features to link the crime and criminals [17]. Gender determination of a footprint becomes critical requirement in estimation of stature from footprints. Earlier researchers have estimated gender based on metric analysis of footprints [12-16]. The differences in ridge density between males and females may be a result of the overall dimorphism. In most of the countries, no footprint database was available in forensic and police departments and hence the investigator has the only choice of comparing the crime scene footprint with potential suspects. In this aspect, gender difference in footprint ridge density becomes relevant during crime scene investigation. The present study was aimed to investigate the gender difference in toeless footprints in Iban population.

\section{Materials \& Methods}

The sample collection was conducted in Sarawak state, one of the states in Malaysian Borneo or east Malaysia, wherein the Ibans are mostly settled here. The study sample consists of consented 200 Ibans (100 males and 100 females) with age ranges from 29 to 69 years. Informed consent from the participants and permission from Chief Minister of Sarawak state were obtained before started 
the sample collection, since Ibans are indigenous ethnic groups in Malaysian Borneo. The footprints were collected following the standard procedure [11-16] and analysed the ridge density in ball and heel area in three regions as shown in (Figure 1).

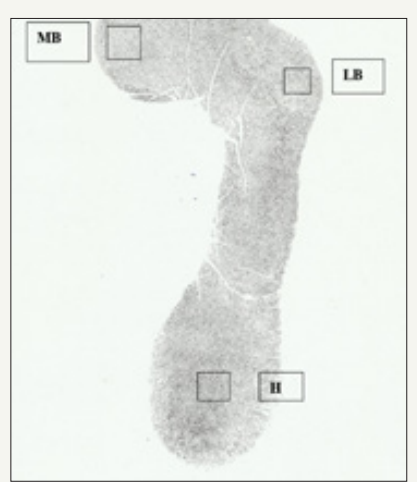

Figure 1: Defined $(25 \mathrm{~mm} 2$ areas) regions on ball and heel area.

The designated regions in the sole of footprint include a) Medial ball, the ball of great toe (MB), b) Lateral ball, below the triradius point on the ball of the $5^{\text {th }}$ toe (LB) and c) Heel, the central prominent part of the heel $(\mathrm{H})$. A transparent square film with $5 \mathrm{~mm} \times 5 \mathrm{~mm}$ size was placed on each (Figure 1) of the region. By using the magnifier, the ridge density or number of ridges in the given space, the count was carried out diagonally as per the method described by Acree [6]. This value represents the number of ridges in $25 \mathrm{~mm}$ square area and reflect the ridge density value. The data were analysed using SPSS software and ridge density for the areas were analysed with independent t-test.

\section{Results}

(Table 1) presents the descriptive statistics of ridge densities in three designated regions in the sole.

The mean ridge density for males in all regions (Lateral ball:10.03 on left and 10.21 on right side, Medial ball: 10.53 on left and 10.75 on right side, Heel: 8.00 on left side and 8.02 on right side) are comparatively lesser than females (Lateral ball: 11.47 on left side and 11.81 on right side, Medial ball:11.81 on left side, 12.18 on right side, Heel: 8.66 on left side and 8.65 on right side). The interesting feature observed in the investigation is the existence of bilateral asymmetry in both sexes. The ridge density in right side is found to be higher than left side in all regions.

Table 1: Descriptive statistics of ridge density in both genders and sides on three regions.

N: Sample size; SD: Standard deviation.

\begin{tabular}{|c|c|c|c|c|c|c|}
\hline \multirow{2}{*}{$\begin{array}{c}\text { Regions } \\
\text { Sex }\end{array}$} & \multicolumn{2}{|c|}{ Lateral Ball } & \multicolumn{2}{|c|}{ Medial Ball } & \multicolumn{2}{|c|}{ Heel } \\
\hline & Male & Female & Male & Female & Male & Female \\
\hline $\mathrm{N}$ & 100 & 100 & 100 & 100 & 100 & 100 \\
\hline \multicolumn{7}{|l|}{ Left side } \\
\hline Mean & 10.03 & 11.47 & 10.53 & 11.81 & 8 & 8.66 \\
\hline SD & 1.521 & 1.684 & 1.077 & 1.253 & 0.974 & 1.157 \\
\hline Range & Jun-14 & Sep-17 & Aug-14 & Sep-16 & 06-Oct & 06-Dec \\
\hline \multicolumn{7}{|l|}{ Right side } \\
\hline Mean & 10.21 & 11.81 & 10.75 & 12.18 & 8.02 & 8.65 \\
\hline SD & 1.458 & 1.751 & 1.336 & 1.507 & 0.943 & 1.058 \\
\hline Range & Jul-14 & Aug-17 & Aug-15 & Aug-17 & 06-Nov & 06-Dec \\
\hline
\end{tabular}

Table 2: Sex differences in the Iban ethnics footprint ridge density on the right and left soles.

\begin{tabular}{|c|c|c|c|c|}
\hline & \multicolumn{2}{c}{ Right Sole } & \multicolumn{2}{c|}{ Left Sole } \\
& t-Value & p- value & t-Value & p-Value \\
\hline Lateral Ball & 7.022 & 0 & 6.346 & 0 \\
\hline Medial Ball & 7.101 & 0 & 7.746 & 0 \\
\hline Heel & 4.447 & 0 & 4.364 & 0 \\
\hline
\end{tabular}

The sex differences in footprint density were found to be statistically significant in all three regions in footprints, as shown in (Table 2). The result findings indicated that maximum sex differences were observed for the ridge density in medial ball are followed by lateral ball and minimum in heel area.
Table 3: Correlation coefficient ( $r$ ) of footprint density of Iban footprint.

\begin{tabular}{|c|c|c|c|c|}
\hline \multicolumn{2}{|c}{ Right Sole } & \multicolumn{2}{c|}{ Left Sole } \\
\hline Sole areas & r-Value & p-value & r-Value & p -Value \\
Heel - Medial Ball & 0.301 & 0 & 0.293 & 0 \\
\hline Heel - Lateral Ball & 0.329 & 0 & 0.342 & 0 \\
\hline $\begin{array}{c}\text { Medial Ball - Lateral } \\
\text { Ball }\end{array}$ & 0.482 & 0 & 0.294 & 0 \\
\hline
\end{tabular}

The frequency distribution of footprint ridge densities in the three designated areas of footprint among males and females in left side and right sides is shown in (Figure 2-4) respectively. The data 
were analysed statistically correlating the ridge density in three areas of the footprint and presented in (Table 3). It is evident that ridge densities in all three areas were statistically correlated with each other.

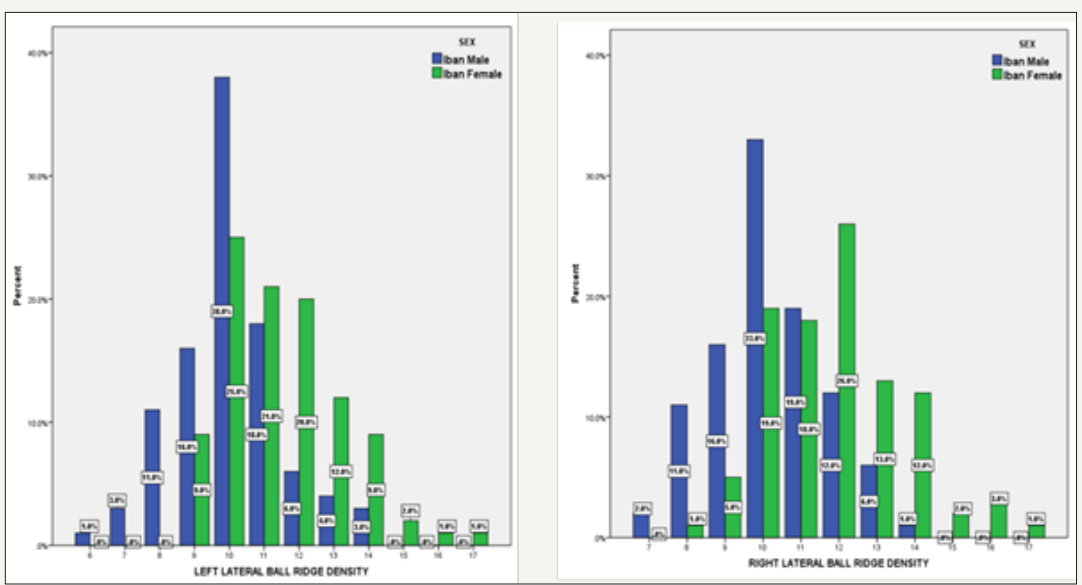

Figure 2: Frequency distribution of footprint ridge density in lateral ball area on both sides.

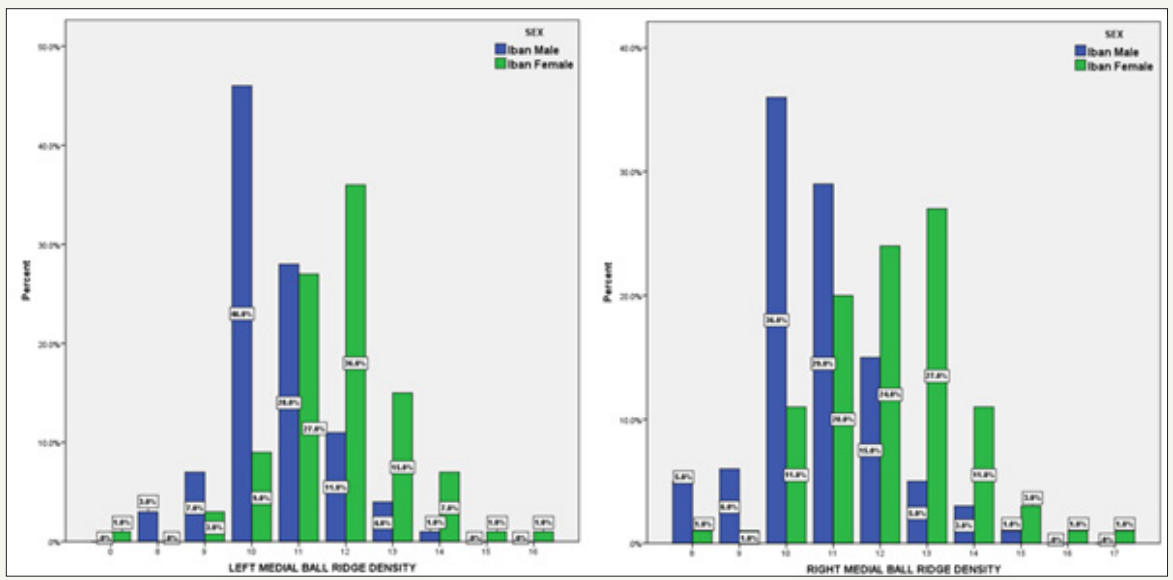

Figure 3: Frequency distribution of footprint ridge density in medial ball area on both sides.

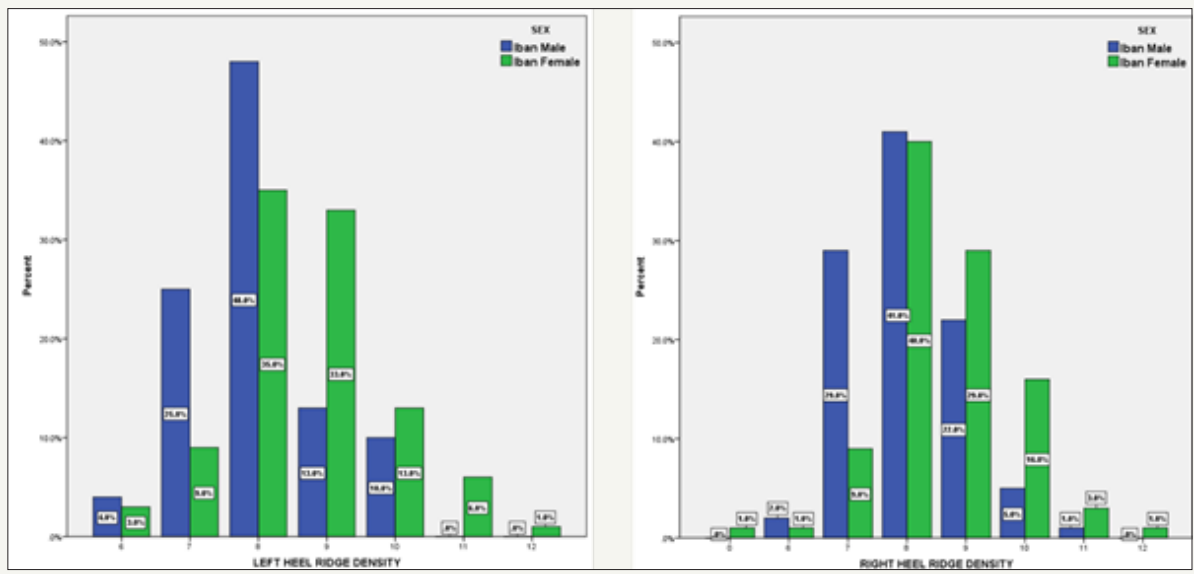

Figure 4: Frequency distribution of footprint ridge density in heel area on both sides.

The ridge density values were analysed by ROC curve, which is a graphical plot that illustrates the diagnostic ability of a binary classifier system as its discrimination threshold is varied. AUC is area under curve. Observations of the ROC analysis to find the predictability of each variable in sex determination are shown in (Figure 5). The AUC in ROC analysis showed that the sexing 
potential was statistically significant, showing ridge density at lateral ball ( $95.7 \%$ on the right and $88.6 \%$ on the left side), medical ball $(94.8 \%$ on the right side, $92.1 \%$ on the left side), and heel
(87.2\% on the right side, $92.6 \%$ on the left side). ROC analysis of the total footprint ridge density shows that the sexing potential of the right and left footprint was $91.6 \%$ and $99.9 \%$ respectively.

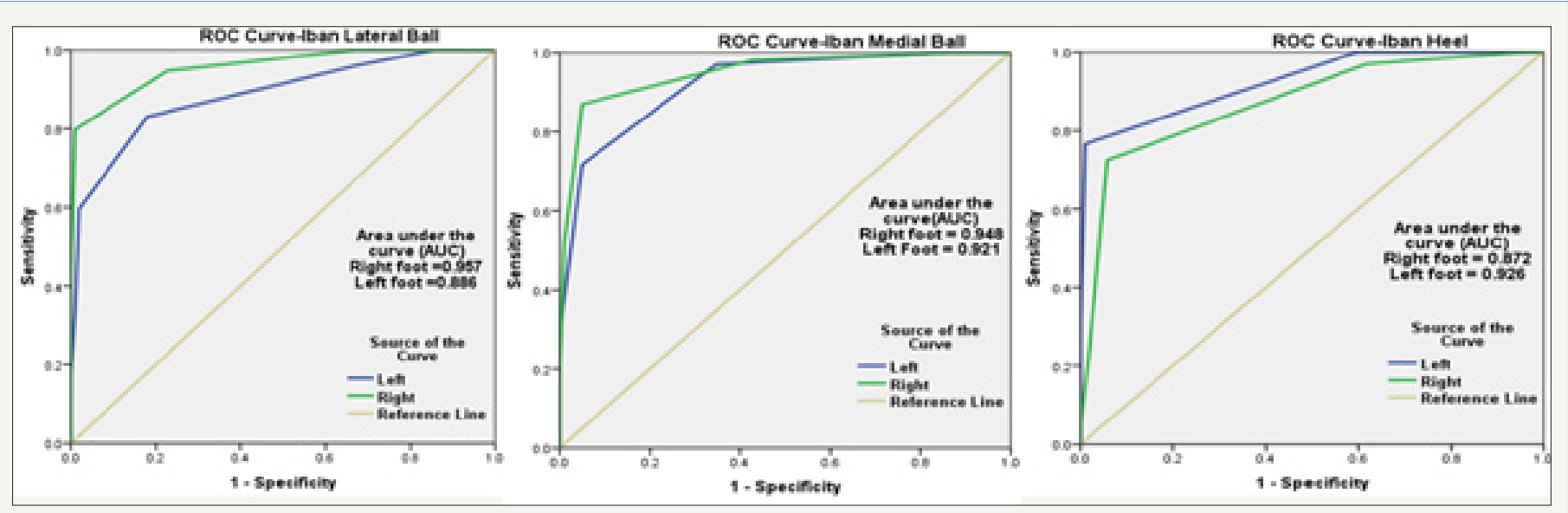

Figure 5: ROC curve for Iban's footprint density in the designated areas.

\section{Discussion}

Human footprint is emerging as a latest biometric trait for biometric authentication for person identification [18]. Literature review shows that many studies were conducted on ridge counts and pattern types in fingerprints [6-9,19]. Footprint evidence can provide more information to the investigators than fingerprints during crime investigation. No footprint database was available in many forensic science and police departments and hence it is mandatory to compare the crime scene footprints with suspects' footprint for inclusion or exclusion and to ease the investigation. In the present study, the sex differences in footprint ridge density in lateral ball (Right:7.002, Left:6.346), medial ball (Right:7.101, Left:7.746) and heel (Right: 4.447, Left: 4.364) are showing a well discrimination threshold in Iban population for sex determination. But these values are entirely different in Indian population (Lateral ball: Right - 4.067, Left - 3.978; Medial ball: Right - 8.422, Left 5.896; Heel: Right - 3.341, Left -3.463) [3]. Similarly, the footprint ridge density in heel area of South African population was 8.84 for left and 8.94 for right side. Thus, the ridge density clearly demonstrated the ethnic variation in this anthropological study for person identification through footprints. The present result findings showed that the footprint ridge density of males is lesser than females in all regions and this finding is in accordance with the previous research findings in other populations. Footprint ridge density has relevance to human morphological studies and contributes to forensic anthropological knowledge through ridge density variation in various regions of the feet sole. Footprints are found mostly in homicide and burglary crime scenes even though the fingerprints were not left by the perpetrators. There are incidences wherein the toe impressions found missed or smudged in the crime scene left as partial footprints. The investigators with lack of knowledge in footprint science have underestimated this evidence, presuming unsuitable for comparison and intentionally neglected in the initial stage of investigation itself and thus missed the chance of person identification [20].

\section{Conclusion}

The study findings provided useful information on sex determination among Iban population in Malaysian Borneo. The footprint ridge density result findings can be very well applied in real crime scenarios for individual identification. The ridge density study in footprint may be extended to other populations so that the genetic basis of sexual dimorphism can be understood and explained in forensic term.

\section{References}

1. Cummins H, Midlo C (1943) Fingerprints, palms and soles. An introduction to dermatoiglyphics. The Blakiston Co, Philadelphia: 227229.

2. Kucken M, Newell AC (2005) Fingerprints, palms and soles. Fingerprint formation. J Theor Biol 235(1): 1019-1025.

3. Kanchan T, Krishan K, Aparna KR, Shyamsunder (2012) Footprint ridge density: A new attribute for sexual dimorphism. J Comp Human Biol 63(6): 468-480.

4. Kennedy RB, Chen S, Pressman IS, Yamashita AB (2005) A large scane statistical analysis of footprints. J Foren Sci 50(5): 1071-1080.

5. Ambeth Kumar VD, Ramakrishnan M (2011) Legacy of footprint recognition - A review. Int J Computer Applica 35(11): 9-16.

6. Acree MA (2009) Is there a gender difference in fingerprint density? Foren Sci Int 102(1): 34-44.

7. Gulterez-Redomero E, Alonso C, Romero E, Galera V (2008) Variability of fingerprint ridge density in a sample of Spanis caucasians and its applications to sex determination. Foren Sci Int 180(1): 17-22.

8. Gulterez-Redomero E, Alsono MC, Dipierri JE (2011) Sex differences in fingerprint ridge density in the Malaco-Maltaguayo population 62: 487499. 
9. Guterez-Remero E, Alonso-Rodriguiz C (2013) Sexual and tropical differences in palm print and ridge density in the Caucasian Spanish population. Foren Sci Int 229(1-3): 159.

10. Laura JH, Ashion MP, Robert S (2016) Comparison of footprint ridge density between South African ethnic groups. J Foren Inves 4(1): 1-4.

11. Nataraja Moorthy T, Ang YL, Saufee AS, Nik F (2014) Estimation of stature from footprint and foot outline measurements in Malaysian Chinese. Austra J Foren Sci 46(2): 136-159.

12. Nataraja Moorthy T, Hairunnisa MAK (2015) Estimation of stature from footprint anthropometry using regression analysis: a study on the Bidayuh population in east Malaysia. Arab J Foren Sci Foren Med 1(1): 13-21.

13. Nataraja Moorthy T, Rasvini A (2017) Determination of stature from dynamic footprint anthropometry in Malaysian Malayalees for forensic investigation. J South Indi Medi Assoc 9(1): 1-7.

14. Nataraja Moorthy T, Hairunnisa MAK (2016) Body weight estimation from various footprint length measurements among Ibans of east Malaysia. Malays Appl Biol 45(2): 113-118.
15. Nataraja Moorthy T, Hairunnisa MAK (2017) Determination of body weight from footprint length measurements among Melanau population. Med Leg Update 17(1): 249-254.

16. Nataraja Moorthy T, Hairunnisa MAK (2018) Body weight estimation from footprint length anthropometry in Lun Bawng ethnic of east Malaysia. Med Leg Update 18(2): 164-169.

17. Nataraja Moorthy T, Siti FS (2015) Individualizing characteristics of footprints in Malaysian Malays for person identification in forensic perspective. Egypt J Foren Sci 5(1): 13-22.

18. Rohit K, Ram CS (2016) Footprint based person recognition using scanning technique. Indian J Sci Tech 9(44): 1-10.

19. Dhall JK, Kapoor AK (2016) Fingerprint ridge density as a potential foresic anthropological tool for sex identification. J Foren Sci 61(2): 424-429.

20. Nataraja Moorthy T (2017) Neglected physical evidence during crime scene investigation. Foren Sci Add Res 1(2): 1-2.
Creative Commons Attribution 4.0

International License

For possible submissions Click Here

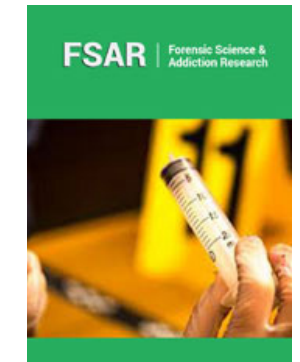

Forensic Science \& Addiction Research

\section{Benefits of Publishing with us}

- High-level peer review and editorial services

- Freely accessible online immediately upon publication

- Authors retain the copyright to their work

- Licensing it under a Creative Commons license

- Visibility through different online platforms 